\title{
Forma y/o contenido: un debate sobre el juicio estético en las obras de arte ${ }^{*}$
}

\author{
J. F. Bhaszar ${ }^{1}$ \\ Universidad de Cartagena
}

\section{Resumen}

El siguiente texto se refiere al debate estético acerca de la preeminencia del análisis de la forma sobre el análisis del contenido de las obras de arte, o viceversa. Se presentan las propuestas y razones que aducen los análisis a partir de los contenidos (what) y los análisis a partir de los estilos o formas (how). La tensión entre estos dos enfoques expone un movimiento de ida y vuelta, no sólo entre los modos de producción, sino también entre los modos de recepción. Inclinarse por el acento en las problemáticas extra-artísticas (filosóficas, sociológicas, políticas), o por la estructura estética (el estilo) de las distintas prácticas artísticas, es la cuestión planteada. Finalmente, y partiendo de una vía intermedia, se reconoce en la producción de obras la imprescindible articulación entre las problemáticas extra-artísticas y las cuestiones de forma y/o estilo, pero se sustenta,

\section{Abstract}

The following text, critical and interpretative in nature, refers to the aesthetic discussion about the preeminence (primacy) of the analysis of shapes over content analysis of works of art, or viceversa. It presents the proposals and reasons given by the analysis based on the content (What) and analysis from the styles or shapes (How). The tension between these two approaches shows a movement back and forth not only between modes of production but also between modes of reception. Inclined to focus on the problems of extra-artistic (philosophical, sociological, political) or aesthetic structure (style) of the various artistic practices, is the subject. Finally and from a middle way, it is recognized in the production works the essential link between the extra-artistic problems and issues of shape and/or style, but is based, likewise, from

\footnotetext{
* Form and content: a debate about the esthetical judgment work of art. Recibido: Abril, 2011 - Aprobado: Agosto, 2011.

${ }^{1}$ Profesor del Programa de Filosofía de la Universidad de Cartagena. Magíster en Filosofía de la Pontificia Universidad Javeriana de Bogotá. Director del Grupo de Investigaciones Estéticas y Culturales "Signos Culturales". Autor del libro La semiótica del arte (2008). e-mail: fellinibarreto@gmail.com
} 
así mismo, desde el horizonte de la recepción la importancia de limitar el análisis del arte a su carácter altamente connotativo, a raíz de la semiótica de cada práctica diferenciada.

Palabras clave: estética, semiótica del arte, objetividad/subjetividad, forma/contenido, estilística. the horizon of the reception the importance of limiting the analysis of art to its remarkable connotative rank from the semiotics of each practice differently.

Key words: art and aesthetics, semiotics of arts, objectivity and subjectivity, form and content, stylistics.

\section{Presentación}

La cuestión de qué es "lo dominante" en una obra de arte plástica (visual), sonora (auditiva) o literaria, a partir de su presentación óntica, o "modo de ser" diferenciado, recupera la pregunta por "la esencia del arte". Una pregunta de este temple se interroga por su rasgo fundamental, es decir, qué sea y cómo sea a la luz de su modo de manifestación originario. Dicho modo parece mostrar que quienes hacen "arte" producen cosas diferenciadas por su carácter típico que las "pro-pone" como signos estéticos que desde un interés particular -poiesis-, apuntan, así mismo, a un interés también particular del receptor (aisthesis). Entonces, productor y receptor coinciden en aquello que tiene de particular la obra "de arte", lo óntico de la obra: el hecho de que sea "del arte" propone el asunto para ser pensado.

Si una obra es una cosa (texto) a raíz de la cual alguien quiere "dejarse oír" de un modo determinado, entonces quien habla (autor) desde ella ha elegido como modo de expresión el rasgo fundamental que los textos artísticos presentan como esenciante, y a su vez, quien acude al encuentro con las obras de arte, acude a "lo" artístico que hay en ellas. "Lo artístico" es un modo (simbólico) de hacerse oír que convoca a quienes quieren oír de ese modo. Pero si "lo artístico" es un modo de presentación (how), tiene que serlo de "algo" (what), es decir, que ello abre las preguntas: 1) ¿qué se deja oír? y ¿cómo acontece esto?; 2) ¿cómo se articulan estas dos cuestiones?, y 3) ¿existe una categorización entre estas dos preguntas?

Se objeta que el "análisis del contenido artístico" constituye un dispositivo subjetivo el cual simplemente tiende a reseñar "lo que es expuesto" con el fin de inferir denuncias sociales, dudosos mensajes políticos y psicológicos, en general, componentes catárticos. Se dice, además, que este enfoque es extra-artístico, porque, más que un interés en la lectura hermética-textual, solamente defiende "el 
alma del autor". Pero así mismo se objeta, por el contrario, que el "análisis de la forma artística" constituye un dispositivo mecánico u objetivo el cual meramente tiende hacia la clasificación detallada de las múltiples connotaciones (también dudosas) derivadas del "cómo es expuesto" el texto a partir de la estructura formal de los particulares lenguajes artísticos; y que, en este sentido, el estilo del autor desafía el análisis completo o la definición de la obra, debido a que el estilo, como el Conde de Buffon (2004) afirmaba pensando en los escritores, "es el hombre en sí mismo".

Ici, Messieurs, l'application feroit plus que la règle; les exemples instruiroient mieux que les préceptes; mais comme il ne m'est pas permis de citer les morceaux sublimes qui m'ont si souvent transporté en lisant vos. Ouvrages, je suis contraint de me borner à des réflexions. Les ouvrages bien écrits seront les seuls qui passeront à la postérité: la quantité des connaissances, la singularité des faits, la nouveauté même des découvertes ne sont pas de sûrs garants de l'immortalité; si les ouvrages qui les contiennent ne roulent que sur de petits objets, s'ils sont écrits sans goût, sans noblesse et sans génie, ils périront, parce que les connaissances, les faits et les découvertes s'enlèvent aisément, se transportent, et gagnent même à être mises en œuvre par des mains plus habiles. Ces choses sont hors de l'homme, le style est l'homme même: le style ne peut donc ni s'enlever, ni se transporter, ni s'altérer: s'il est élevé, noble, sublime, l'auteur sera également admiré dans tous les temps; car il n'y a que la vérité qui soit durable et même éternelle. Or un beau style n'est tel en effet que par le nombre infini des vérités qu'il présente. Toutes les beautés intellectuelles qui s'y trouvent, tous les rapports dont il est composé, sont autant de vérités aussi utiles, et peut-être plus précieuses pour l'esprit humain, que celles qui peuvent faire le fond du sujet (9-11. Las cursivas son nuestras) ${ }^{2}$.

\footnotetext{
2 "Aquí, Señores, la aplicación haría más que la regla; los ejemplos instruirían mejor que los preceptos; pero así como no me está permitido citar extractos sublimes que me transportaron a menudo, leyendo vuestras Obras, me veo obligado a limitarme a reflexiones. Las obras bien escritas serán las únicas que pasarán a la posteridad: la cantidad de los conocimientos, la singularidad de los hechos, la misma novedad de los descubrimientos, no son seguros garantes de la inmortalidad; si las obras que los contienen giran sólo alrededor de pequeños objetos, si están escritas sin gusto, sin nobleza y sin genio, perecerán, porque los conocimientos, los hechos y los descubrimientos, se levantan fácilmente, se transportan, y ganan incluso a seres
} 
En cierto sentido ambos puntos de vista son dignos de mención, pero, equivocados o no, parecen presentados por críticos radicales que se rehusarían a aceptar que la escritura es un proceso misterioso en el cual la forma confluye con el contenido-asunto y viceversa. A este respecto, parece que los defensores de la forma han olvidado que el hombre "is immortal, not because he alone among creatures has an inexhaustible voice, but because he has a soul, a spirit capable of compassion and sacrifice and endurance" y que "the poet's, the writer's, duty is to write about these things", como William Faulkner expresó al recibir el premio Nobel ${ }^{33}$ (Frenz, 1969: 2). Del otro lado, los defensores de lo que T. S. Eliot llamó "sociological theory" y "historical explanation" (Drew, 1970: 1-25) parecen haber olvidado que la tarea y meta de todo escritor, de todo artista, es adquirir precisión y nuevas significaciones de la naturaleza paradójica del lenguaje: "easy writing for the reader is difficult writing for the writer", como Turner (1973: 200) escribió en su Estilística.

Entonces, la pregunta por cuándo las prácticas artísticas están dedicadas a la propagación de una idea particular o creencia, y cuándo es cuestión de estilo o técnica, se constituye en una situación de gran debate. Muchos artistas destacados han usado el arte para exponer sus posiciones políticas, filosóficas, psicológicas o religiosas, con el fin de llamar la atención de las personas hacia las manifestaciones materiales de una sociedad. Con respecto a esto, los partidarios de la forma argumentan, con buena razón, que lo que estos escritores comprometidos escriben no es asunto de la literatura y el arte, sino de la sociología, la política o la filosofía, y, en muchos casos, de la propaganda:

puestos a la obra con manos más hábiles. Estas cosas están fuera del hombre, el estilo es el hombre mismo: el estilo no puede entonces ni quitarse, ni transportarse, ni alterarse: si es elevado, noble, sublime, el autor será igualmente admirado en todos los tiempos; porque no existe sino la verdad que sea duradera y hasta eterna. Entonces, un bello estilo, no es tal en efecto sino por el número infinito de verdades que presenta. Todas las bellezas intelectuales que se encuentran, todas las relaciones por las que son compuestas, son tantas verdades tan útiles, y posiblemente más preciosas para el espíritu humano, que las que pueden hacer el fondo del tema". (La traducción es nuestra).

3 "I believe that man will not merely endure: he will prevail. He is immortal, not because he alone among creatures has an inexhaustible voice, but because he has a soul, a spirit capable of compassion and sacrifice and endurance. The poet's, the writer's, duty is to write about these things. It is his privilege to help man endure by lifting his heart, by reminding him of the courage and honor and hope and pride and compassion and pity and sacrifice which have been the glory of his past. The poet's voice need not merely be the record of man, it can be one of the props, the pillars to help him endure and prevail" $(1,2)$. 
If an author sets out to make a case for a particular religious, social or political point of view, through the medium of a play or a novel, for example, and he is seen to be doing this, and perhaps in the process he sacrifices verisimilitude by contriving character and situation to suit his thesis, then it might be said that the result is a work of propaganda (Cuddon, 1982: 534).

Sin embargo, aquel argumento podría atenuarse:

If what he has to say is worth reading or listening to long after the issue which provoked the propaganda is dead, then his art has transcended the contingent needs of the propagandist (534).

Esto implicaría que la propaganda, en el mejor de los casos, requiere el arte de trascender; y como afirman los formalistas, el arte es cuestión de estilo y técnica, y esa técnica no es sólo el método, sino también el objeto del arte. A primera vista, aquellos críticos que rechazan el arte como un "espejo del hombre" -y conciben el arte como carente de interés ideológico- podrían estar expuestos a que una ideología llamada de izquierda los redujese al slogan "burgeois provinces". Podrían argumentar en su defensa, sin embargo, que por medio del análisis exhaustivo de un texto artístico el crítico puede descubrir los niveles de participación del significado que se encuentran debajo de las intensiones y la superficie consciente del escritor.

Ahora bien, si el arte, por ejemplo la literatura, es una cuestión de estilo y técnica, los estilistas pueden revelar que el dominio de cada lengua implica el dominio de los estilos formales, técnicos e informativos, así como del estilo conversacional y el confesional. En resumen, para reivindicar a los partidarios de la forma lo ideal sería, en palabras de Brecht, "to write for the people in the language of kings", utilizando todos los recursos acumulados en estilos una vez confinados a las clases altas y desarrollados a través de siglos de civilización (Turner, 1973: 230). Es evidente que este debate abre otro igual, o más inagotable: el debate acerca de "qué sea el arte y sus prácticas artísticas”. Ello merecería una atención aparte. Responder a esta pregunta significaría, en cierta medida, la complejidad de justificar nuestras convicciones, pues implica una cuestión de "ideología", o en otras palabras, un problema de actitudes particulares acerca de qué sea el mundo o los horizontes de interpretación de las múltiples realidades posibles. 


\section{Subjetividad y objetividad poiética ${ }^{4}$}

Cuando aplicamos la subjetividad a la producción artística, esto implica que el artista está emotivamente (pathos) involucrado con las experiencias y sentimientos personales, como en la autobiografía o en la ficción en la cual la subjetividad permanece oculta: A Portrait of the artist as a young man (1984), de James Joyce, Otto e mezzo (1963), de Federico Fellini, o casi toda la pictórica romántica de Caspar D. Friedrich, etc. La objetividad sugiere, contrariamente, que el artista se auto-pone onto-estéticamente fuera de aquello de lo que él está escribiendo; se ha desconectado y expulsado a sí mismo del texto, y al hacerlo, está preservando lo que Bertolt Brecht denominó como Verfremdungseffekt (efecto de alienación o distancia estética): una buena parte de la pictórica de Giorgio Chirico, el teatro brechtiano, la escultórica de Constantin Brâncuşi y varios filmes de Peter Greenaway, como Zoo (1985-6), Una z y dos ceros (1986), etc. El primero suele tender a la conexión emotiva (catharsis) de los receptores; el segundo, a la conexión reflexiva (análisis crítico):

The term (aesthetic distance) implies a psychological relationship between the reader (or viewer) and a work of art. It describes the attitudes or perspective of person in relation to a work, irrespective of whether it is interesting to that person. A reader may dislike a poem, for instance, for subjective reasons but this should not vitiate his objective reaction. The reader or critic has at once to be involved with -and detached from- what he is concentrating on. The work is "distanced" so that it may be appreciated aesthetically and not confused with reality. The writer bears the responsibility for gauging and determining the distance (not in any spatial sense) at which his work should be reviewed. If he bullies the reader into attending, then his reader may be repelled. Conversely, if he undertakes too much, then his reader may not get the point (Cuddon, 1982: 17).

En otras palabras, el ejercicio de lo que Keats (1991) llamó "negative capability", es decir, "when a man is capable of being in uncertainties, mysteries, doubts, without any irritable reaching after fact and reason" (5). Las novelas de Henry James, y en cierta medida, los poemas de Philip Larkin muestran una objetividad marcada (664). No obstante, es posible una reconciliación de las

\footnotetext{
${ }^{4}$ Subjetividad y objetividad son dos términos importados a Inglaterra gracias a la filosofía del criticismo pos-kantiano alemán de finales del siglo XVIII.
} 
ideas de este debate: cualquier artista con algún mérito estético se auto-pone simultáneamente entre lo subjetivo y objetivo. Está subjetivamente absorto en su trabajo: la calidad e intensidad de su visión personal es expuesta, pero, al mismo tiempo, debe retirarse de "su" texto, y controlar así su obra. De este modo, el autor está involucrado en una actividad paradójica: un acto intelectual de armonía creativa en el cual la invención y el juicio se juntan para lograr el equilibrio (664).

A primera vista, la objetividad pura requiere artistas fundamentalmente involucrados con la estructura formal, con las herramientas y posibilidades técnicas de cada lenguaje artístico, más que las almas inmortales y perseverantes de Faulkner. Así, si el artista es básicamente un "arquitecto del diseño y el estilo", ello puede suponer que "lo que" él dice (muestra) puede no ser tan importante como "el modo" en que lo dice (lo muestra); la estructura formal del texto (kinestésico, plástico-visual o sonoro-auditivo) lo es todo -como muchos formalistas pretenden-, y en consecuencia, la función de la crítica es para "inspeccionarlo cerradamente" (close reading). Desde esta perspectiva, la interpretación y correspondiente evaluación crítica de las obras de arte estarían inscritas dentro de un estudio de la articulación de los lenguajes artísticos: análisis al interior de las prácticas artísticas a partir de las distintas semióticas que las especifican como ámbitos autónomos y diferenciados.

Por otro lado, si nos atenemos literalmente a Buffon, si tenemos en mente que "el estilo es el hombre mismo", como se señalaba al principio, parece surgir una contradicción ya señalada por el psicoanálisis lacaniano. En esta posición, el estilo del escritor o el artista (como un hombre particular que escribe cosas) puede ser observado como un asunto de subjetividad, ya que "eso" es tan peculiar a él como sus propios gestos (en resumen, la voz y el tono del autor mismo). Si definir la estructura formal para el arte es "like trying to put a sack of flour in a thimble" (663), como Remy de Gourmont apuntaba acerca de la literatura y el estilo, el análisis formal de las obras parece ser menos objetivo que lo señalado por muchos críticos. En ese mismo sentido, si el análisis formal de las obras es una teoría o ciencia, entonces, ¿es el arte el producto final de sus cómputos (cálculos)?, ¿es la literatura como un vaso de agua?: "language is like water, tasteless and cold", como apuntaba Walter Hilton (1991: 39). Asumiendo una posición escéptica que daría una posible salida a esta disputa estética, permítasenos recuperar una idea más de Turner, uno de los estilistas más destacados de nuestro tiempo: 
There may be many such unconscious preferences in all of us, ultimately caused by complex elements in our makeup that can hardly be analyzed even with the aid of such modern devices as psychoanalysis and the psychological study of personality (Turner, 1973: 22).

Pero el estudio de la literatura y el arte es notablemente diferente al del análisis de la personalidad. El artista es un edificador de mundos simbólicos desde los diferentes marcos estructurales de las respectivas prácticas artísticas (semióticas de las artes plásticas, literarias, musicales, etc.), pero también es un sujeto que tiene una voz personal habilitada para dar testimonio individual o colectivo de su tiempo, un fabulista intérprete que fabrica situaciones, "inventa" palabras, sonidos, texturas e imágenes que pueden hacen reír, entristecer y soñar: un deicida vargallosiano. La literatura o el arte, no son un vaso de agua, insípido y frío, sino una situación en la que el lector (o el crítico) es un intérprete que se detiene a observar las antiguas verdades universales, las implicaciones humanas de su subjetividad y su inserción social e histórica.

En definitiva, se podría señalar desde una perspectiva mediadora, que "el análisis de los textos artísticos no existe por sí mismo"; lo que realmente lo hace interesante son aquellas disciplinas y áreas del conocimiento que están directa o indirectamente conectadas con la propia naturaleza real de la humanidad, como, por ejemplo, la filosofía, la psicología, la sociología, la antropología y otras parcelas relacionadas, por un lado, y por otro, los juiciosos análisis que versen sobre la técnica, el estilo y las posibilidades formales que abren las articulaciones de los lenguajes al interior de cada práctica artística.

En estos términos, se podría rápidamente concluir que los análisis de what is said y how it is said están inextricablemente interrelacionados en la crítica práctica. En resumen, en el terreno del análisis artístico la literaturnost de raíz jacobsiana (Pozuelo, 1989: 36, 41-49) confluiría con la weltanshauung (Dilthey, 1949), tal como el poeta italiano Giuseppe Ungaretti (2005) lo mostró en uno de sus más bellos poemas en donde se reafirma que la literatura es "il mondo l'umanità" y "la propria vita" (what), pero la palabra, "fioriti dalla parola" (how), es aquella "limpida meraviglia" que sitúa a la literatura en el terreno del arte: 
Gentile

Ettore Serra

Poesia

È il mondo l'umanità

La propria vita

Fioriti dalla parola

La limpida meraviglia

Di un delirante fermento

Quando trovo

In questo mio silenzio

Una parola

Scavata è nella mia vita

Come un abisso ("Commiato", 169) 5 .

Y sin embargo... podría caber otra reflexión que partiría de la producción hacia la recepción.

\section{Arte e ideología: articulación, no reducción}

Los productores de obras de arte pueden exponer si desean o no problemas de ordenes filosóficos, políticos, psicológicos y sociológicos en sus obras. No están obligados a hacerlo o a no hacerlo. No existe ninguna normatividad o verdad supra-estética que pueda imponerlos, que pueda exigirlos. Los clásicos tratados acerca del arte como los de Aristóteles, Horacio, Longino y Boileau son hoy en día apenas referentes textuales para algunos artistas, para la teoría estética/reflexiva y la filosofía del arte; no, en cambio, lineamientos rígidos e inamovibles para la experiencia productiva de los artistas. El zeitgeist de estos textos aún nos susurra de modo admirable la experiencia originaria que atestiguó su fundación, pero nuestro horizonte actual de lectura los mira con recelo.

La exposición o no de tales cuestiones, no justifica, como le contesta Ernesto Sábato a Alain Robbe-Grillet (1963), la omisión del trasfondo humano, o mejor aún, el rasgo espiritual de toda obra ("pues es harto sabido que los personajes fundamentales de una novela salen del corazón del propio autor, y es muy tonto o muy mal escritor o muy candoroso si hace la comedia de la prescindencia o la objetividad" [114-115]), o en el sentido hermenéutico, desvirtuar el carácter

${ }^{5}$ DESPEDIDA. "Amable/ Héctor Serra/, poesía/ es el mundo la humanidad/ la propia vida florecida de palabras/ la límpida maravilla/ de un fermento delirante/ Cuando encuentro/ en este silencio mío/ una palabra está cavada en mi vida/ como un abismo." Poema que aparece en la primera edición de "Il Porto sepolto", Locvizza, 2 de octubre de 1916. (Traducción de Wenceslao Maldonado). 
histórico/humano de los textos, el rasgo fundamental de toda obra por abstracta que parezca ser. Ningún autor, así se lo proponga, puede nihilizar a nombre de una literatura o arte distanciado (objetivado) el horizonte existencial e histórico que otorga sentido a todo texto.

Atendiendo al mismo tiempo al what is said y al how is said, debe indicarse que las problemáticas de fondo (sociológicas, psicológicas), los personajes y sus tramas, y así mismo la forma de las obras (el decorado y las texturas, los tonos y los ritmos) son inventados en el alma del artista. Por ejemplo, los personajes o sujetos de una obra -si los hay- hablan de vez en cuando, sospechan, aman, especulan acerca de la realidad -emocional o política/económica-: una cierta realidad aparentemente (que aparece) "figurativa" o "abstracta" que los soporta, una realidad elegida de modo deliberado por el pulso del autor como contrapartida de otras posibles, o como si no las hubiese (que algo sea o no sea con este volumen y no aquel otro, esta silla roja y no más bien aquella también roja). En últimas, "el autor no puede estar si no presente" (1963: 121) en su obra; no existe algo así como lo que se llamaría "el autor distanciado", o la poiesis objetivada. Sus decisiones expresan sus intervenciones. La "obra de" arte es ella misma una "intervención del" artista en la "realidad-real" (Mario Vargas Losa, 1971: 85). Lo contrario de todo esto -si se pudiesesería la puesta en marcha de un autor extrañado del texto, como si nada tuviese que ver con él, escindido de la realidad figurativa o abstracta que él mismo decidió inventar. Otra vez, un vaso de agua insípido y frío.

Pero, así mismo, ¿cómo presentar aquello que se quiere presentar de tal modo que lo presentado sea aproximado a aquello que se quiere presentar? Hegel (1989), reflexionando sobre la antropomórfica escultura griega, nos dice:

[...] De ahí que lo sensible por sí mismo no retenga ninguna expresión que no sea la delo espiritual, lo mismo que a la inversa, la escultura no puede representar con perfección ningún contenido espiritual que no pueda plasmarse adecuadamente en forma corporal. Pues por la escultura el espíritu ha de estar silencioso y feliz en su forma corporal, en unidad inmediata con ella, y la forma ha de estar vivificada por el contenido de la individualidad espiritual. Así, el material sensible externo ya no es elaborado meramente según su cualidad mecánica, como masa pesada, ni al color, etc., sino en las formas ideales de la figura humana, y esto según la totalidad de las dimensiones espaciales (78). 
Autores "abstractos" desde diferentes flancos del terreno de las prácticas artísticas, como Michelangelo Antonioni (cine psicológico), Ingmar Bergman (cine filosófico), Jean Paul Sartre (narrativa filosófica), Chirico (pintura metafísica), Brecht (teatro político) o Brâncuşi (escultura formal simplificada) presentan obras tomadas como meramente "distanciadas", que parecen eliminar no sólo al autor, sino también la comunicación con el espectador. Sin embargo, no es esto lo que acontece. No son cuerpos fríos. Los canales de comunicación receptiva con dichas obras se abren precisamente porque, en realidad, ninguno de sus autores se ha escindido de su producción y porque jamás podrán hacerlo. Brecht mismo no sólo ha puesto en escena "su" técnica distanciadora para con los espectadores tratando de eliminar la catarsis, sino también "su" ideología de base, "su" crítica moral, "su" insatisfacción ante el hecho de que "el" mundo (eso) sea como es o parezca ser así (lo óntico), inhumano y vergonzoso. En una frase, Brecht también "ha puesto sus" emociones.

Los simbolismos "fríos" e "impersonales" de Brâncuşi y Chirico son exactamente eso, simbolismos puros, expresiones mínimas, pero espirituales e históricas que metamorfosean la realidad humana a nombre de otra. En otras palabras, un esquema o trazo original manifestado como "lenguaje" que trata de "decir" espiritualmente algo, pero apuntando desde otra parte. Antonioni, igualmente, desde una cifrada y árida semiótica expositiva de los temas, y reflexionando siempre sobre su propio lenguaje, explora problemáticas de profundo interés psicológico y sociológico (incomunicación femenina, industrialización); Sartre y Bergman, por su parte, examinan con un lenguaje abstruso y de exigente conceptualización para los receptores la cuestión del absurdo de la existencia y la toma de posiciones que sus personajes asumen al respecto.

Ahora bien, todos estos autores, y todo artista, auscultan las problemáticas de su interés o presentan sus temas (formales o de contenido) desde las herramientas técnicas y formales que les brinda el propio arte, es decir, a partir de las articulaciones de los distintos lenguajes artísticos desde donde se refieren a sus receptores. Sin importar si es arte "distanciado" o catártico (de identificación), las problemáticas o temas son examinandas por el artista a la luz de las posibilidades técnicas de la imagen, de la palabra, del sonido, de las texturas, etc. Es decir, desde el estilo y la riqueza significativa (connotativa) de cada expresión artística, la cual se abre hacia la ambigüedad polisémica. El artista se refiere al mundo y desde el mundo, a partir del "lenguaje" que ha elegido para "hablar". Resueltos por uno u otro, pintura, música o literatura, "los artistas se decidieron por el arte" y su articulación. Emplazados en el terreno de las prácticas 
artísticas como un destino que veían venir, aceptaron sin dilaciones, y ya sin resistencia, morir a la realidad real y sus lenguajes (lenguas naturales y artificiales), aniquilar la consciencia y sus productos (palabras de base, deseos, miedos), para reinventarse ellos mismos y a la realidad "desde" el arte, para re-fundarse "desde" otro campo de realidad que apenas parece un "lenguaje".

El artista no se refiere al mundo propiamente a través de los puros conceptos y la fundamentación teórica de las ideas (forma/ metodología disciplinar) que tenga acerca de la realidad, como ideologías de base, sistemas filosófico, teoría social; y a veces ni siquiera a través del "conocimiento" del lenguaje mismo del arte y sus posibilidades significativas. Autores sin escuela estética, como la nouvelle vague, o rigurosamente formados por los Gremios de finales del Medioevo; profundamente ideológicos y conceptuales como los cineastas italianos de los años 60/70, o exponentes catárticos de la música popular -melodramática y cacofónica-, como en la balada romántica latina y americana de los años 80 , todos, sin excepción, se decidieron por el arte y sus distintos lenguajes de expresión.

En este sentido, y más allá de si hay cuestiones filosóficas, psicológicas o políticas en una obra, el asunto medular es el carácter limitado del arte para permitir conceptualizaciones de problemas teóricos (argumentación y fundamentación, ideas mediadas por el pensamiento), y en correspondencia, la cuestión de la óptica u horizonte desde donde debe valorarse/juzgarse una obra. Debido a que el terreno del arte es demasiado limitado por su espacio/tiempo de exposición, y por el carácter ambiguo de sus producciones, altamente connotativas, los problemas propuestos por los autores al interior del arte rebasan el campo artístico. Posiblemente por ello muchos han acudido, como Pasolini, Mario Vargas Llosa, Thomas Mann, León Tolstoi, Wassily Kandinsky, etc., a la escritura de libros, ensayos cortos, textos académicos, presentación de entrevistas o asumen cátedras universitarias que motivan la discusión. En estos "lenguajes artificiales" (Lotman, 1988: 20), en cambio, tienen la libertad de presentar sus tesis mediante un libre desarrollo argumentado y con una parcela mayor de exposición temática, pues la palabra escrita de estos textos especializados les permite mayor campo de trabajo compensado muchas veces con el debate. Desde estos lenguajes extraartísticos, los problemas se examinan o investigan desde los puros conceptos (filosofía) y desde las teorías y tesis que, en muchos casos, se sopesan con sistemas de medición como porcentajes, entrevistas, muestreo, talleres, etc. (sociología, psicología). 
Respecto al arte, cabe acotarse que la misma naturaleza deformativa (deconstructiva) y ambigua del arte (Eco, 1984) permite que los mismos artistas se enfoquen en el lenguaje que usan de acuerdo a la semiótica de la expresión elegida, y adelantándose siempre hacia sus riquezas posibles: semióticas del cine, la escultura, el teatro, performances, etc. Ejemplos límites lo conforman los documentales reflexivos, la escultura abstracta de Brancusi, las pinturas suprematistas de Kasimir Malevich, las piezas atonales de Arnold Schöemberg. Exploran el lenguaje del arte mediante el propio lenguaje. En ese sentido, los receptores medios, la crítica y el correspondiente análisis de las obras, lo que observan son los bosquejos de problemáticas, simples esquemas graficados de temas sin un tratamiento conceptual filosófico, sociológico o psicológico de fondo que pueda sostener las diversas tesis que de allí se desprendan. Así, pues, sería muy difícil exponer de modo detallado teorías del ámbito de la sociología, proyectos filosóficos completos, problemas teológicos, en una palabra, verdaderos sistemas de pensamiento, con la mera obra de arte como único lenguaje de rigurosa exposición conceptual, esperanzándose, a lo mejor, en un autodidactismo a raíz de imágenes, de volúmenes, de aromas, de metáforas, de narradores omniscientes, de retruécanos, de movimientos tonales, etc.

Si se propone al cine documental expositivo o a una suerte de "literatura-ensayo" como articulaciones de problemáticas sociales/ filosóficas con el manejo de técnicas y estilo artístico, deben señalarse algunas cuestiones complejas a partir de la experiencia estética receptiva. En el documental, si se sigue la imagen, desoigo la voz en off (esta es la justeza del cine); si se sigue la voz (que me trasporta lejanamente a lo conceptual, sacándome), desatiendo la imagen; si es un filme rodado en un idioma extranjero, y no se conoce y se sigue la subtitulación, peor: se mira triangularmente con énfasis en la parte inferior de la pantalla. Si se piensa un caso límite de documental, donde un narrador hable directamente a la cámara, de modo personal, y sin interrupción de imágenes aleatorias (y posiblemente sin repeticiones), debe señalarse que se hace más difícil para el espectador seguir los conceptos por medio de la palabra dicha. Además, semejante producto sería una propuesta estética -si es que la es- que bien podría reemplazarse por un texto escrito que dijese lo mismo de modo más exhaustivo y unívoco, y en definitiva, se constituiría más bien en una teleconferencia o en un programa informativo y/o educativo de la televisión, en los cuales se presentan discursos muy cortos y claros para la múltiple audiencia, sin argumentaciones prolijas y diversidad de ilustraciones y contextualizaciones. Meros esquemas informativos de corta duración que nunca, por su naturaleza de eficacia y rapidez, dirigida 
a muchos espectadores, constituyen un sistema de pensamiento, una teoría decantada de modo ordenado, y por largo tiempo, un proyecto de explicación histórica de la realidad.

Una "literatura-ensayo" o la literatura que intentase presentar al tiempo un sistema ordenado y teórico del pensamiento ("una" filosofía, un proyecto de reflexión antropológico, etc.) y una narración o poema, terminaría haciendo no una, sino varias cosas bastante diferentes en el mismo volumen. Por momentos historia y por momentos literatura, a veces filosofía (o más bien historia de ella), a veces prosa o verso... Paradiso (1976), de José Lezama Lima, hace algunas de estas incursiones, y pareciese que recogiera con un solo aliento toda la experiencia originaria de un momento de la cultura cubana, la monumentalidad de la historia y de los saberes posibles. Pero esta prosa barroca, y demasiado alquitarada, dejó puestos los cerrojos para los contenidos temáticos de mayor hondura conceptual que ahí se exponen. Otras obras de este carácter pueden presentar ciertas cuestiones de disciplinas extra-artísticas, pero usualmente se experimentan como "apiñadas", tratando de hacer una cosa para justificar otra: narrando algo a expensas de la presentación filosófica de un dilema moral o de un desarrollo argumentativo, por ejemplo, o del otro lado, presentando exiguas reflexiones filosóficas para tratar de otorgar sentido fundamental y así legitimar el discurso literario.

De otro lado, y para recuperar la cuestión central de este ensayo, es decir, el lugar desde donde se deben mirar las obras (o lo que se debe mirar en ellas), es necesario un viraje de la producción a la recepción: el artista ha elegido un modo de ser percibido, el lenguaje artístico. Si el arte es un "sistema de modelización secundario", como consideraba Yuri Lotman (1988: 20), que, como lenguaje, es diferente a los lenguajes especializados de las ciencias y sus metalenguajes ("lenguajes artificiales"), ello presentaría a las prácticas artísticas como expresiones del lenguaje secundario que superan las meras reflexiones sociológicas, políticas, filosóficas y psicoanalíticas, y las cuales exigen procesos de crítica a un nivel diferente. ¿Cuáles? Al nivel de las posibilidades y herramientas de cada semiótica artística como campo de múltiples significaciones estéticas. Su dominante. Una dominante que es de corte altamente connotativo, por su ambigüedad o apertura.

Es en este sentido que aquí -últimamente- se ha venido insistiendo en la "preeminencia ontológica" de la crítica y análisis de las obras a partir de las dinámicas particulares de cada práctica artística (estructura del guión, dramaturgia, fotografía, ritmo, asimetrías, intensidades, tropos, texturas, fragancias, funcionalidad del espacio, 
etc.), y no de las problemáticas sociales, psicológicas o filosófica halladas en las obras.

Las segundas apreciaciones se legitiman a la luz de las valoraciones estéticas, no a la inversa.

Es claro que el análisis de un texto de Bob Dylan o de una película de Welles resulta diferente si el analista es un crítico artístico, un antropólogo o un sociólogo. Cambia el punto de vista y en consecuencia lo hace la dominante de la estructura jerarquizada, lo que podríamos definir como principio ordenador o gesto semántico del texto. No es, pues, que una lectura antropológica o sociológica falsee el texto. Ambas producen sentido a partir de datos que también están incluidos en el texto. Sin embargo ello no debe llevarnos a pensar como supuesto corolario lógico, que la lectura estética coexista -sea una más-con las anteriormente citadas y todas aquellas que puedan realizarse. Muy al contrario es ella la que impone la manera en que todas las demás deben hacerse. En una palabra, la dominancia estética consiste en una forma específica de organizar los elementos diversos y el valor de todos ellos depende del que le otorga su posición dentro de esa estructura que la dominancia estética articula (Talens, 1995: 22).

De allí que muchos autores, apostándole sus productos a conceptos extra-artísticos, abandonándolos a las ideologías de base, han perdido de vista la dominancia en el arte y el buen gusto estético, "el ennoblecimiento de las formas", produciendo obras extravagantes y de escasa calidad estética, como el cine ruso de la filosofía del tractor, una buena porción del muralismo mexicano y de las artes plásticas de la Cuba posrevolucionaria: ese arte defendido por Tolstoi (1999), verdaderos bodrios para la experiencia estética placentera; irrisiones del arte que la crítica argentina Marta Traba (1961) alcanzó a aniquilar. Se trata de artistas que, por las razones que sean, han tratado de "teorizar demasiadas cosas" en un espacio muy reducido para ello -pero, por eso mismo, muy amplio para las iniciativas estéticas- y con las herramientas inadecuadas.

Quiere (todo) ello decir que los componentes políticos e ideológicos, aunque integrantes de dicha unidad estructurada, no son tampoco los que definen las especificidad del texto artístico en cuanto tal. La reducción del arte a la política o la ideología (y, 
subrayamos, la reducción, no la articulación, ella sí imprescindible) propia, todavía, de ciertos cultivadores de un marxismo mal llamado ortodoxo (nunca Marx, Engels, Lenin o Mao cayeron en tal simplismo), supone eliminar la especificidad del espacio artístico como espacio de trabajo y, en consecuencia, eliminar también la posibilidad misma de producir un discurso teórico que dé cuenta del arte como práctica humana y social diferenciada" (Talens, 1995: 24)

Esta otra postura no niega que en una obra puedan coexistir elementos formales y de contenido, a consciencia o no del autor. Muchos de estos ni siquiera él los ha pre-visto: cuestiones extraartísticas (filosóficas, políticas) y también estilísticas de las que él no se da por enterado. Al fin y al cabo los lectores son sus principales críticos (no él). Pero eso no significa que la crítica o análisis de las obras deba apuntar a dichos elementos propios de los "lenguajes artificiales" como su target. Como ya se dijo, el autor no está obligado a presentar problemáticas de esa índole; tal vez sólo se haya decidido a contar historias pueriles y frívolas de escasa durabilidad, o por qué no, larga. Sólo se refiere al mundo desde el arte: lo ha elegido para ser oído, usualmente indagando desde el propio lenguaje artístico por sus posibilidades técnicas y formales.

No se trata de si es arte burgués o de izquierda, "comprometido" o no con una ideología o proyecto filosófico. El único compromiso del autor es con las posibilidades abiertas que le presenta cada expresión artística desde su articulación propia (dominancia estética/semiótica). Más específicamente, el compromiso del autor/artista es con el color, con las texturas, con los sonidos, y correlativamente, con las sensaciones que "expresa" a los demás, luego de haber sido "impresionado"; participar sus percepciones de luces, sonidos, sentimientos y emociones, porque ya no los "resiste".

Así, si el artista desea narrar una historia, puede ser lo más sencilla posible, la anécdota más simple, puede ser minimalista; tampoco tiene que ser el tema que le interese a la mayoría de espectadores (la violencia en las grandes ciudades, el narcotráfico, la niñez desamparada), sino sólo a un círculo cerrado, como el problema de los arquitectos que propuso Greenaway, o la cuestión de las formas en Malevich, o los suicidios de los jóvenes en Japón, o las guerras en cierta fracción de África o en los Balcanes, o la lucha por la siembras y la tierra en el lejano Oriente, no importa. La pregunta es: ¿cómo presentó el autor esas problemáticas? Estructura de guión, construcción de los personajes, raccord de luz, modelo de 
actuación, duelo de metáforas, voces (primera persona, tercera persona, narrador omnisciente), retruécanos, cajas chinas, temples tonales, dodecafonías, métricas, texturas suaves ó duras, frías o secas, fragancias, contrastes de ritmo y proporción, barro y madera, calicanto, vidrieras, lapislázuli, ámbar u oro, arcadas, triforios, la piedra brillante resistiendo el mar...

\section{Bibliografía}

Cuddon, J. A. (1982). A Dictionary of literary Terms. New York: Penguin Books.

Dilthey, W. (1949). Introducción a las ciencias del espíritu. México: Fondo de Cultura Económica.

Drew, E. (1970). T. S. Eliot. The Design of his poetry. Delhi: Eyre and Spottiswoode (Publishers) Ltd.

Eco, U. (1984). Obra abierta. Barcelona: Planeta- De Agostini.

Frenz, H. (editor, 1969)). Nobel Lectures, Literature 1901-1967. Amsterdam: Elsevier Publishing Company.

Hegel, G. W. F. (1989). Estética. Barcelona: Ediciones Península.

Hilton, W. (1991). The Scale of perfection. New Jersey: Paulist Press.

Keats, J. (1991). Poesía completa. Barcelona: Ediciones 29.

Lotman, Y. (1988). Estructura del texto artístico. Madrid: Ediciones Istmo.

Leclerc, G. L \& Conde de Buffon. (2004). Discurso sobre el estilo. México: Universidad Nacional Autónoma de México.

Pozuelo. J. M. (1989). Teoría del lenguaje literario. Madrid: Cátedra.

Sábato, E. (1963). El escritor y sus fantasmas. Buenos Aires: Aguilar. . (1968). Tres aproximaciones a la literatura de nuestro tiempo: Robbe-

Grillet, Borges, Sartre. Santiago de Chile: Editorial Universitaria.

Talens, J. (1995). "Práctica artística y producción significante". En Tallens, J. et.al. Elementos para una semiótica del texto artístico. Madrid: Cátedra, pp.17-60.

Tolstoi, L. (1999). ¿Qué es el arte? México: Editorial Alba.

Traba, M. (1961). La pintura nueva en Latinoamérica. Bogotá: Librería Central

Turner, G. W. (1973). Stylistics. Aylesbury Bucks: Hazell Watson y Viney Ltd. Ungaretti, G. (2005). L'Alegria. Milano: Mondadori.

Vargas Llosa, M. (1971). Historia de un deicidio. Madrid: Seix Barral. 
